\title{
Franck Salaün, L'autorité du discours. Recherches sur le statut des textes et la circulation des idées dans l'Europe des Lumières
}

\section{Simón Gallegos Gabilondo}

\section{(2) OpenEdition \\ 1 Journals}

\section{Edizione digitale}

URL: http://journals.openedition.org/studifrancesi/5617

DOI: $10.4000 /$ studifrancesi.5617

ISSN: 2421-5856

\section{Editore}

Rosenberg \& Sellier

\section{Edizione cartacea}

Data di pubblicazione: 1 septembre 2011

Paginazione: 406

ISSN: 0039-2944

\section{Notizia bibliografica digitale}

Simón Gallegos Gabilondo, «Franck Salaün, L'autorité du discours. Recherches sur le statut des textes et la circulation des idées dans l'Europe des Lumières», Studi Francesi [Online], 164 (LV | II) | 2011, online dal 30 novembre 2015, consultato il 10 janvier 2021. URL: http://journals.openedition.org/studifrancesi/ 5617 ; DOI: https://doi.org/10.4000/studifrancesi.5617

Questo documento è stato generato automaticamente il 10 janvier 2021.

\section{cc) (†) $\odot$}

Studi Francesi è distribuita con Licenza Creative Commons Attribuzione - Non commerciale - Non opere derivate 4.0 Internazionale. 


\title{
Franck Salaün, L'autorité du discours. Recherches sur le statut des textes et la circulation des idées dans l'Europe des Lumières
}

\author{
Simón Gallegos Gabilondo
}

\section{NOTIZIA}

FRANCK SALAÜN, L'autorité du discours. Recherches sur le statut des textes et la circulation des idées dans l'Europe des Lumières, Paris, Honoré Champion, 2010, 450 pp.

1 L'affermazione del philosophe come protagonista della vita intellettuale nel corso del xviII secolo è un processo di grande complessità le cui conseguenze sono difficilmente misurabili in tutta la loro estensione. Il presente studio di F. Salaün esamina i presupposti di questa problematica considerando l'Illuminismo a partire dai rapporti che esso stabilisce con il concetto di autorità.

2 La questione di stabilire chi parla nei testi di filosofi e scrittori, e sulla base di quale diritto, è il problema di fondo che scorre attraverso i diversi autori presi in esame (d'Holbach, Rousseau, Diderot, Foucault, Kant, Deslandes, Marivaux, Gauchat, Prévost), all'interno di una riflessione sul discorso in quanto pratica, cioè sul modo nel quale la società accetta, rifiuta e modifica le idee, mettendo in atto valori e regole. La posta in gioco consiste nella definizione dei criteri di credibilità dei discorsi, e si concentra nella difficile domanda sull'origine dell'autorità di un testo, autorità che nel Secolo dei Lumi è oggetto di forti attacchi e di altrettanto forti difese. Tanto il bisogno di riaffermazione della legittimità dei poteri tradizionali, quanto quello di un loro radicale ripensamento generano delle pratiche discorsive, che insieme al concetto di autorità emergono come oggetto specifico di questo libro. 
3 La delegittimazione di alcune correnti filosofiche mira al ripristino di un'autorità che andava incontro ad una crisi profonda. In questo senso, ad esempio, il pensiero materialistico appare come una minaccia all'autorità politica e religiosa, in quanto veicolo di altri valori rispetto a quelli dominanti. Risulta essenziale dunque lo studio delle regole a partire dalle quali si generano tali discorsi, dal punto di vista della produzione e della ricezione dei testi e specialmente della gerarchizzazione di tali discorsi, i cui riflessi vengono esaminati dall'autore tanto nei libri di filosofi quanto in romanzi e opere teatrali.

4 Il processo di affermazione dell'intellettuale si riflette in un'abbondante produzione letteraria, nella quale i philosophes possono occupare un luogo centrale, per diventare in qualche occasione oggetto di satira. Queste messe in scena sono testimoni diretti del conflitto tra rifiuto e ripristino della tradizione, che F. Salaün ci propone di osservare considerando le dinamiche che si sviluppano intorno al concetto di autorità.

5 Talvolta il lavoro filosofico e quello letterario possono confluire in un'inaspettata complicità: contro una vecchia tradizione che condanna il riso, in un libro messo all'Indice, Deslandes ne fa invece un elogio, in nome di una visione dell'esistenza secondo lui più adatta alla natura umana. Anzi, lo scrittore rivendica un riso filosofico nel quale non vi sia contraddizione rispetto alla ragione, per l'appunto, in vista di una liberazione dall'autorità dei pregiudizi. 